\title{
A New Paradigm for the Method of the Social Sciences
}

\section{Angelo FUSARI}

\author{
Capo la Villa di Tornimparte, via Cerasolo, 6, 67049 L'Aquila, Italy
}

\begin{abstract}
Keywords: Traditional Methodologies; Social-Historic Process; Organizational Necessity and Choice-Possibility; Civilizations; Ethics.
\end{abstract}

\begin{abstract}
This essay begins by pointing out the pointlessness of the great theories on method, that is the abstract rationality and the observation-experimentation ones, to describe and understand social reality. Then we consider the multiplicity of alternative hypotheses and methodologies that have been directed to remedy the difficulties of the above two methods in treating social phenomena. Soon after, we set out an interpretation that bases the method of inquiry on social reality on a model privileging the organizational side. We pay attention to the classification and interaction of basic and particularly meaningful aspects of social reality, as well as on the methodological distinction between the organizational "necessity" of social systems (that is, required by reasons of organizational rationality and efficiency) and "choice-possibility" as centered on the civilization options and choices. This will allow the defining of an interpretative model based on the action of man as builder and organizer of social systems, an interpretation able to understand the main vicissitudes of those systems. We shall consider the deceits that the Roman Church derived from her renunciation of the medieval organizational vision, under the suggestion of the successes gained by the observational-experimental method in the study of natural reality. We shall also consider the effects of the misunderstandings above, mainly in the field of ethics. Finally, we shall dedicate some attention to the theory of social and historical processes.
\end{abstract}

\section{Introduction}

Method is, in our time, in a condition in some sense hybrid. Some questions pertaining to method are currently treated with great severity and in some sophisticated ways, while others stagnate in a condition of great confusion, appearances notwithstanding, sometimes mixed with an apparent severity that makes the confusion almost indecipherable.

It is opportune to distinguish the current method and philosophy of sciences in three courses, starting from the first born in forms able to stimulate fecund and rigorous teachings. More precisely, we start with the most abstract and ancient of them, concerning mathematics and logic-formal sciences. This method is based on what may be called "abstract rationality" criterion, consisting in the deduction of logical implications from postulates largely abstracted from factual reality. Such a high degree of abstraction allows explanations characterized by a high degree of generality, sometimes able to offer unexpected solutions as do, for instance, Boolean algebra and nonEuclidean geometries that derive from logical abstractions apparently almost unreal, but which have shown in due time precious in facilitating calculations, in astronomic exploration and the formulation of general theories such as Einstein's theory of relativity. Euclidean geometry is the most relevant application of this method.

The analysis of more specific aspects of reality has experienced for a long time a substantial methodological fragility, mainly in the interpretation of the natural world and interaction with it. In fact, the method of the natural sciences has remained for a long time in an equivocal condition, often having known an embarrassing retrocession with respect to Archimedes" contributions based on experimentation.

Precisely, knowledge of the natural world was obstructed for a long time by the habit of basing research on premises that abstracted from the observation of factual evidence. An example: Aristoteles explained the disappearance of some birds in winter with the hypothesis that they went into hibernation in the bowels of the Earth. Such an explanation was accepted for almost 1500 years, until the emperor Fredrich the second of Hohenstaufen, who understood through accurate 
observations that the disappearance of some birds was due to their migration to hotter countries. Despite the evidence of the importance of observation to natural phenomena, official observations and experiments have been shelved from official science in other centuries. The opposition of the Church to Galileo is often attributed to biblical citations such as Joshua's command to the sun to stop. In effect, the Ptolemaic representation of the geocentric solar system implied a substantial privilege of the earth, located at the centre of Universe by the Creator. In consequence of this explanatory reference to God's will, the heliocentric theory formulated by Aristarchus of Samos was put aside.

The debate on universals, centered on the opposition between nominalism and realism, that is, whether definitions were nominal or real, characterized the discussion on method for a long time. The domination of Aristotelian-Ptolemaic thinking pushed theoretical meditation on a road attractive and rich in culture and in reference to the role of reason; yet a road completely in the wrong direction with regard to the analysis of the natural world as centered on the idea that the role of natural science is to penetrate the reason why God has created the world such as it is. True enough, a disregarded number of irregular and heterodox students, such as alchemists and magicians, trusted in the importance of experiments, even if sometimes with senseless purposes for instance, the search to discover the philosophers" stone. In the end, Francis Bacon and even more Galileo Galilei clarified the inappropriateness of the organizational medieval criterion based on the understanding of the reason behind the organizational forms established by God for the natural world. Such a vision of nature as directed to the understanding of the impenetrable will of God, which in fact each religion represents differently from others, was replaced by the observation-experimental method anticipated by Archimedes, which bases the study of natural phenomena on the cooperation of mathematics and observation, mainly through mathematical models directed to express laws of motion of nature, and submitted to verification through accurate observations and experiments on the phenomena in question.

The observational-experimental method is based on the hypothesis of repetitiveness of the considered phenomena: a hypothesis largely reflected by the natural world, except in the case of catastrophic events. Such a hypothesis substantially operates in primitive (quasi-stationary) societies and also with regard to natural phenomena that know mutations in very long periods of time, for instance the Darwinian apparition of new species over millennia.

However, the idea of repetitiveness can be referred to a very low number of social phenomena. Therefore, our analysis needs to be extended to an excluded middle, that is, the definition of a method that is appropriate to social thinking.

The great success of the Galilean observational-experimental method caused the extension of this method to other realities, including the social one. But under an adjustment: to the idea of strong observationism, that is, for the condition of repetitiveness of phenomena and the acceptance of existence was substituted the idea of feeble observationism, only concerning the acceptance of existence. This is the idea of spontaneous behavior, according to which the considered phenomena would spontaneously converge toward rational and efficient solutions. Such an idea marks Mandeville's analysis of "the vileness of ingredients that constitute on the whole a healthy mixture for society", due to the transformation through competitive process of private vices into public virtues. A similar idea is expressed by the Smithian notion of the invisible hand and by Hayek's celebration of spontaneous order. Max Weber expressed the substance of the interpretation above through the principle of "diffuse rationality", according to which in the long run the behavior of society gravitates towards rational and efficient solutions. Unfortunately, such an automatic adjustment is not warranted in a world incessantly shaken by social change. What's more, we must not only consider the long run; we must consider also the medium and short run.

Traditional methodology is not suitable for human social reality, which means that something different are needed. In consequence, there have grown up a variety of proposals on method centered on particular aspects, more or less relevant, of social reality, resulting in a very fragmented and deceitful heterodoxy due to its limitations and incompleteness. Derived from this is an analytic interpretative variety unable to allow uniform criteria of verification and comparability of achieved 
results, and the Feyerabendian negation of method.

\section{Analytic Categories Able to Provide Reliable Foundations for Social Knowledge}

We turn now to the main point of this analysis: how to provide an organizational methodological vision for the study of human society, in order to remedy the drawbacks just analyzed. The basic content of this study on the method of social thought starts here. The building of social thought needs to couple positive and normative aspects, being and doing. It must mistrust mere observation of existence and combine observation and organization. Precisely, we have to immerse ourselves in the basic character of social reality as organized and built by man; this seems to be the most appropriate way to understand and govern its contents and becoming. It follows that the obligatory starting point of the analysis of human societies is the differentiation of basic characters of social reality that may be able (and directed) to allowing the understanding of its behavior.

First, it is necessary to identify and distinguish the factors causing non-repetitive changes of social events and hence proceed to consider, in the course of those events, the following phenomena: organizational "necessity" imposed by reasons concerning rationality and efficiency of a social system; and "choice-possibility-creativity" in the becoming of human societies. The above conditions respectively express the phenomena of structural organization and innovation of social systems. But it is needed, first of all, to consider the non-repetitiveness due to creativity and innovation, and hence the contents of a reality qualitatively different from the natural one.

To begin with, we have to consider and identify the conditions expressing the most peculiar aspects and contents of social reality, that is, expressing human creativity and innovation and hence the intrinsic and growing (with development) non-repetitiveness of human societies. We denominate those conditions "ontological imperatives". They embody necessary conditions for allowing the expression and operation of evolutionary potentialities innate in human nature. The action of these imperatives in the life of human societies, therefore the operation of human evolutionary potentialities, is not warranted. They can be suffocated by social orders adverse to their effectiveness. This will obstruct the evolution over time of those societies that would remain motionless for centuries and millennia in a substantially repetitive condition, similarly to natural reality. The action of ontological imperatives will, on the contrary, totally change such behavior, thus causing, through the advent of the non-repetition of social events, the requirement of an approach on method completely different from the observation-experimental method of the natural sciences.

It may be useful to specify some of the most important ontological imperatives, that is, institutional forms pushing human action toward creativity and innovation and so to build new worlds. The examples of ontological imperatives that follow are aimed at reducing the abstractness of our analysis on this subject.

An important ontological imperative is represented by the division of labor, as this is an important tool for the expression of human constructional potentialities. This ontological imperative plays an important role in promoting organizational efficiency and social evolution; of course, with the condition that labor division reflects individual skills, that is, expresses the evolutionary potential inherent to human nature.

Another fundamental ontological imperative concerns the role of the individual, this being a primary source of creativity and hence of the variety of social processes. Such a role implies the decentralization of choice and decision processes. This imperative needs the operation of personal dignity, and a personal responsibility principle to warrant the profitableness of individual action. An ontological imperative associated with this is the reciprocity sentiment as indispensable in the promotion of social cohesion.

There is also an ontological imperative flanking the principle concerning autonomy, dignity and sacredness of the individual, is the principle of tolerance toward dissidents; it is indispensable in allowing a systematic confrontation between different view points, and is indispensable to the evolution of knowledge in a world populated by beings endowed with limited skills; this in turns points to the need for pluralism and social justice, which constitute therefore other important 
ontological imperatives necessary to promote the utilization of human creative skills, these being dispersed by chance among human beings.

The degree of propulsion of each social system depends on the presence and incisiveness of ontological imperatives. The presence or absence of these imperatives expresses the degree of openness or closeness of considered societies towards novelties.

A further fundamental classification required by the study of human societies is represented by what we denominate "functional imperatives". These imperatives concern organizational forms imposed, in the presence of some levels of the general conditions of development, by reasons of efficiency and the organizational rationality of social systems. As such, these imperatives are determined by the operation, over time, of human evolutionary potentialities and precisely by the corresponding ontological imperatives; therefore, they markedly differ from Talcott Parsons' functional imperatives.

It is easy to understand that the persistence of the dynamism of human societies, that is, the acquisition of general conditions of development characterized by such a persistence, needs the institutionalization of the ontological imperatives considered above, which in this way will also become functional imperatives, that is indispensable to the existence of societies expressing persistent dynamism. This means that the following are required: the role of individual initiative and the connected principles of responsibility, of pluralism and tolerance. Some functional imperatives are not in operation today, such as the principle of social justice and the practice of power as service. They are replaced, as sources of social dynamism, by some other important functional imperatives, for instance (and as capitalism teaches us), by the central role of entrepreneurship with the connected skill and propensity to innovate, to meet in the course of development process the high level of radical uncertainty due to the non-stationary character of the economy, and to perceive and anticipate with versatility changes in course. The entrepreneurial role and the phenomenon of radical uncertainty imply a connected functional necessity of the market as information and coordination tool in the presence of high and systematic uncertainty. Also, the nonmonopolistic rate of profit is a functional imperative as an indispensable measure of efficiency and the degree of success of entrepreneurial action and decisions. Our book, A new economic for modern dynamic economies (Routledge 2017), develops in detail these aspects that, together with the establishment of the economic system on the centre stage of modern dynamic societies, constitute important functional imperatives. These imperatives are much more than basic instruments of the work of capitalism as expressed by the almost spontaneous development of the Western world, that is, a world expressing a kind of society (capitalism) that, as we shall see, expresses a specific civilization. A modern non-capitalist social system (and civilization), however evolutionary and dynamic, cannot do without them, for reasons of efficiency and organizational rationality. In addition, the notion of power-service, the alternative to power as domination, will become a functional imperative in advanced societies.

In capitalism, important ontological imperatives are violated, particularly those concerning justice, income distribution and service-power. But the progress of the general conditions of development will attribute also to these ontological imperatives the character of functional imperatives, in this way pushing toward the overcoming of capitalism. Those imperatives can be specified through models rich in mathematics.

The previous outline on ontological and functional imperatives makes evident the following important law of social development. With the advancement of the general conditions of development pushed by the operation, in the considered social system, of ontological imperatives, these also become functional imperatives, that is become organizational necessities of the resulting societies. In fact, societies omitting the observation of these imperatives, that is failing to be consistent with the phase of development at work, will be destroyed by internal inefficiencies and contradictions and by the competition with those societies that do satisfy those imperatives. So, functional imperatives represent some gravitational centers during processes of spontaneous development. Knowledge of them is indispensable to prevent their advent being obstructed by particular interests of dominating classes. 
Many examples concerning the advent, over time, of those organizational forms can be documented. For instance, in primitive societies parental organization displays the central role of functional imperative, independently of the peculiarities and the eccentricity of the various kinds of relationship, as shown by the analyses of Levi-Strauss. The multiplications of social functions and differentiations, the development of transportations and of the dimensions of territorial groups and of exchanges causes the necessity of more sophisticated social organizations. More impersonal power forms than those typical of parental organization are born side by side with the necessity of "command power", in the substitution or superimposition of the "power of society" on human behavior characterizing life in primitive societies. The phenomenon of "companions in arm" and other organizational forms expressing the first kinds of command power start to transform themselves in forms of "state power": imperial or national states with the connected centralization of political power. The conquest by the economy of a central position in the social process has caused the advent of some functional imperatives previously discussed, both in the economies operating on markets regulated by demand-supply and in those characterized by market power. In this second case, the functional imperative concerning the "control of effective demand" becomes operative, as directed to avoid deficiency of demand. Economies in the phase of take-off require institutions and strategies able to deactivate the development trap and, later on, the trap of dualism.

The rapid increase today of international exchanges and the advent of the "global economy" point to the need for new economic institutions and power forms that favor both the needs of decentralization and the advent of federalism among national states. In a parallel line, the need for an extension of the forms of reciprocity as necessary to warrant social cohesion also appears. The entry onto the scene of the masses in contemporary societies increases the need to combine operational efficiency and social justice also through the separation of the firm from the conflict for income distribution, and so make the market "a pure mechanism for imputation of costs and efficiency" (we have abundantly discussed this aspect in our two books on A new economics for modern dynamic economies and Understanding the course of social reality). The same base technologies required by new phases of development can be considered functional imperatives.

We see, therefore, that the specification of ontological and functional imperatives needs an organizational vision on method, that is, one based on the notion of the organizational rationality of social systems.

\section{Necessity and Choice-Possibility in the Edification and Functioning of Human Societies}

We must now dedicate attention to a fundamental distinction implied by the organizational vision on method: what represents "necessity" and what expresses "choice-possibility" in the organization of social systems. Organizational necessities are not a matter of observation. In fact, history teaches that they can largely be ignored in practice and even strongly denied. Choice-possibility has no an observational character as it concerns choice. Yet such impossibility of observation does not imply the impossibility of understanding and treating this question.

To understand social processes, it is imperative to concentrate first of all on the organizational necessities distinguishing them. The study of historic processes, for instance, the transition from feudalism to the merchant societies in the middle Ages, clearly shows the "necessity", in each phase of development, of forms of power, ethical values, particular visions of the world, and their pointlessness in other situations. History teaches us that the operation of spontaneous tendencies toward existing or emerging organizational necessities has often generated great torments and, in case of failure, that social systems have been forced to go backward towards previous phases of development. It may be useful to provide some examples of organizational necessities.

The first students of capitalism were fascinated by the functioning of the economy through spontaneous processes. They considered this due to the work of the market, to which some of them attributed the character of natural law. But the market is simply an organizational necessity of modern dynamic economies that arises due to the impossibility of meeting radical uncertainty (which strongly characterizing such economies) through centralized decision making. Here we do not consider further organizational necessities as it is sufficient to recall, in this regard, the notion of 
functional imperatives.

Instead, we must concentrate on "choice-possibility" that, as such, implies conflict. In this way we complete the representation of social reality, both through the consideration of long run options and their implications, and of more detailed questions. The specific character of any one social system will depend on the articulation of choice-possibility as dependent, first of all, on the advent of innovations.

Some aspects of choice-possibility have long duration and substantial implications and assume the forms of civilizations. Here an important aspect of our exposition emerges: the difference between necessity and duration. Long run options, with large implications, such as those concerning civilizations, do not express organizational necessities but are a result of choice-processes and express the most fundamental ideological choices around which the whole social reality is structured and integrated. They may be denominated "great options". Examples include: the "idea of progress", typical of the Western world: "conformism" and "obedience culture", typical of bureaucratic-centralized and autocratic orders. These great options (or key ideas) are the result of very long processes of elaboration and can be removed only with much gradualness, during long periods of time involving nations, ideals, behaviors, institutions, in sum the building of a new social universe in place of the existing one. As such, they constitute an important factor of continuity.

The "civilizations" express the institutionalization of ideological and technological choices expressed by great options, with the implied organizational forms and conditionings of the natural environment. But the notion of civilization differs from that of society or social system, being less inclusive than both. In fact, it excludes functional imperatives and basic technologies, as these concern every society, for some given level of the general conditions of development; it also excludes technologic choices and innovations not yet institutionalized.

Clearly, the notions of civilization and functional imperatives, even if both concern the long run, differ in a basic character: the first expresses a choice, while the second concerns the formulation of a general principle and "necessity". Civilizations, as a result of choice, have a conflicting content. Differently from functional imperatives, they do not vary with the changes in the general conditions of development; they have a strong propensity to preserve themselves. Their birth marks periods of intense creativity, but their inclination to preserve themselves is a cause of sclerosis. By contrast, functional imperatives have not a conservative character since they vary with the general conditions of development and, for given general conditions of development, place people and nations under similar organizational exigencies.

The advent of new functional imperatives drives existing civilizations towards extinction and promotes new ones consistent with the new functional imperatives, hence more efficient, competitive and, in sum, more appropriate to the new conditions of development.

\section{Analysis of Ethical Aspects Obliges Some Considerations}

It now becomes indispensable to consider a very delicate and involved aspect of social reality that is nevertheless condemned to heavy misunderstandings and omissions by the domination of the observational-experimental method. We refer to ethics, which expresses the most peculiar aspect of social reality and, in some sense, the true typicality of this reality as edified by man. The observational-experimental method is not suitable to formulate explanations on ethics; and it is forced to accept this as it is, that is, to consider it impossible to provide a scientific explanation. The result is the domination of the notion of "cultural relativism", that is, the acceptance of existing ethical values as something important but impossible to explain, in sum, something which is not a scientific subject.

In short, the observational-experimental method is unable to edify a science of ethics, an aspect of reality that is extremely important for the government of human societies. Of course, religions do not accept this kind of agnosticism on ethics, that is, the relativist assumption that all ethical values have, in principle, equal (that is zero) dignity and that, therefore, men can freely choose among them. Therefore, religions oppose to cultural relativism a substantial "cultural absolutism", according to which ethical values would be an object of faith; and are satisfied to see that cultural 
relativism has as its counterpart only cultural absolutism. Unfortunately, such absolutism subjects paralyze the ethical issues of opposites, which are made particularly disturbing by the central importance of ethics in the government of human societies. Clearly, human reason is obliged to see in this condition of knowledge a great lack of scientific thought, which has caused heavy and insoluble conflicts over the course of history.

This absurdity, represented by the presumption that science is powerless in the face of ethical values, clearly shows the poverty and dangers of the observational-experimental method when referred to the analysis of social reality; it clearly appears that the government of human societies must strongly distrust such a method. However, it emerges that to go beyond this disastrous scientific impotence caused by the extension of observational (and/or abstract rationality) visions to social reality requires a change in vision, a turn towards a method appropriate to social reality as produced by man. This is the organizational vision that, as such, is suited to understand why and how man has built his social world, including its ethical content, and the best way to organize and govern it.

This is something analogous to the organizational vision of the Medieval Church that thought to explain the reason why the Creator has organized natural world in the way we see: a deceitful pretension that, as we saw, was defeated by the Galilean observational method. Unfortunately, the great success of such a method deleted the reference, even if fecund, of the organizational vision to the study and administration of human societies which, as a consequence, has known an inappropriate extension also to them of the observational and abstract-rationality methods or, as previously seen, of a growing and confused methodological pluralism, as an answer to the growing failures of the observational method in social thought.

Well, questions of ethical values indicate the road we are obliged to take to overcome such confusion. In other words, it indicates that ethics can be scientifically treated only on the basis of an organizational view, that is, one centered on the problem of the edification and administration of human societies. Indeed, the ethical aspect is a fundamental passage of the organizational approach that we have defined, and a major propellant toward it. Moreover, it is the only path able to turn the ethical question, of such crucial importance in the working of any social system, from the dead end of cultural relativism and autocracy. The notion of functional imperative plays a fundamental role in the solution of the enigma. In fact, we have seen that important functional imperatives concern ethics. For instance, value premises concerning institutional decentralization, pluralism, confrontation with different theories, individual initiative and service-power constitute organizational necessities for the existence and efficiency of modern dynamic societies. It may be useful to remember that the imperatives above play an important role in the evangelic teaching, but notwithstanding this, their central importance has been ignored. Cultural relativism and absolutism do not exhaust the question of ethical values. There is much more; precisely, there is what may be called "cultural objectivism", consisting in the scientific explanation of important aspects of ethics.

The analysis of ethical aspects obliges some considerations on the notion of utopia. In fact, such a notion intensively expresses ethical-ideological aspects. Utopia concerns choice and, as such, can clash with civilizations and cause great fractures. A fundamental propulsive role is expressed by utopias that "anticipate" new functional imperatives and that establish ontological imperatives. These utopias strongly accelerate development processes. Christian prophecy on the role and dignity of the individual is an important example of this kind of utopia. But there is also the opposite case of utopias contrasting with ethical aspects concerning existing or future functional imperatives. These utopias operate as degenerative phenomena and the competition among social systems will obscure them, notwithstanding the forces, illusions and particular interests that operate in their favor.

\section{The Interpretation of Historic-social Processes}

Our analysis of social process can be easily extended to the interpretation of history. Such an extension needs a notion of "historic phase", intended as resulting from the character of the general conditions of development at work. This allows, on the basis of the previous treatment of social 
processes, the interpretation of the historic processes that follows: the action of ontological imperatives will determine the evolutionary behavior of social system. This will cause changes in the general conditions of development, that is, new and more advanced historic phases, which will demand the advent of new functional imperatives, that is, new and more advanced organizational forms able to warrant the rationality and efficiency of the new social order. In the long run, this may imply that the emergence of new civilization coincides with the new functional requirements in the process of innovation and construction of the historical process.

In this process, creation and innovation act as engines of the whole process, while the organizational structuring that follows, over the course of social edification, act to remedy the inconsistencies raised and hence to prepare the conditions that will promote a new innovative dash. A fundamental role of social thought is the distinction of "organizational necessity" from "choicepossibility", that is, to acknowledge both functional imperatives and great options (which characterize civilization choices), thus avoiding that these choices may be inconsistent with functional imperatives.

In some sense, historical events may be considered as laborious and prolonged institutional elaborations operating in the phase of development through which society is moving. Historic process results in a motion along subsequent phases of development, each one of them incorporates the inheritance of past conditions, opens the door to the phase that will follow and imposes some game rules to observe, thus avoiding the accentuation of torments due to trial and error process to which historic becoming would otherwise be obliged,

\section{Summary}

We have seen that social science must be based on an organizational vision of human societies. More precisely, it must start with the definition of general principles and the classification of the considered reality according to some important interpretative and organizational categories. Moreover, it must define great options that give rise to civilization forms. In a parallel line, the operation of choice-possibility will determine, on the wave of successful innovations and side by side with the great options on civilization forms, the advent of particular and specific aspects of the studied reality. As is evident, all this has nothing to do with the observational-experimental method of the natural sciences, nor to the method of abstract rationality typical of logic-formal and mathematical sciences (or a combination of both methods, as frequently found in economics).

\section{References}

[1] Boudon, R. (2005). The poverty of relativism. Oxford: Bardwell

[2] Di Nuoscio, V. (2006). Il mestiere dello scienziato sociale. Napoli: Liguori Editore

[3] Ekstedt, H. e Fusari A. (2010). Economic theory and social change. Problems and revisions. London/New York: Routledge

[4] Feyerabend, P. K. (1975). Against method. Milano: Feltrinelli

[5] Fusari, A. (2014). Methodological misconceptions in the social sciences. Rethinking social thought and social processes. Dordrecht, Heidelberg, New York, London: Springer

[6] Fusari, A. (2016). Understanding the course of social reality. The necessity of institutional and ethical transformations of utopian flavour. Springer, Switzerland

[7] Fusari, A. (2017). A new economics for modern dynamic economies. Innovation, uncertainty and entrepreneurship. New York and Abingdon Oxon: Routledge

[8] Galilei, G. (2001) Sidereus nuncius. Letteratura Universale / Esperia

[9] Hayek, F. A. (1949). Individualism and economic order. London: Routledge \& Kegan Paul

[10] Hayek, F. A. (1999). The fatal conceit. The errors of socialism. Chicago: University of 


\section{Chicago Press}

[11] Hegel, G. W. (1987). Enciclopedia delle scienze filosofiche in compendio (A. Negri Ed), Bari: Laterza

[12] Hermann, A. (2015). The sistemic nature of the economic crisis. The perspecives of heterodox economics and psychoanalysis. Routledge, Abingdon and New York

[13] Hobbes, T. (2006). Leviatan. Roma: Editori Riuniti

[14] Hodgson, G. M. (1988). Evolution and institutions. Chelthenam / Northampton: Edward Elgar

[15] Hume, D. (1997). Un”inchiesta sui principi della morale. Laterza: Bari e Roma

[16] Kant, I (1982). The critique of pure reason. The critique of practical reason. The critique of jujudgements. William Benton Publisher / Enciclopedia Britannica

[17] Kuhn, T. (1978). The structure of scientific revolutions. Torino: Einaudi

[18] Lakatos, I. (1984) “The history of science and its rational reconstruction”. In, I. Lakatos \& A. Musgrave (Eds.). Citicism and growth of knowledge. Milano: Feltrinelli

[19] Lawson, T. (2006). “The nature of heterodox economics”, Cambridge Journal of Economics, 30. 483-505

[20] Levi-Strauss, C. (1968). La vie familiale et sociale des Indiens Nambikwara. Paris: Societé des Americanistes

[21] Mandeville, B. (2000). The fable of bees. Bari: Laterza

[22] Myrdal, G. (1966). Il valore nella teoria sociale. Torino: Einaudi

[23] North, D. C. (1993). Institutions, institutional change and economic performance. Cambridge: Cambridge University Press

[24] Pareto, V. (1960). Oeuvres complete (publié sous la direction de G. Basino). Genève: Librairie Droz

[25] Parsons, T. (1987). The structure of social action. Bologna: Il Mulino

[26] Pellicani, L. L. (2006 ). La genesi del capitalismo e l"origine della modernità. Cosenza: Marco Editore

[27] Pera, M. (1982). Apologia del metodo. Bari: Laterza

[28] Popper, K. R. (1976). The poverty of historicism. London/Hanley: Routledge \& Kegan Paul

[29] Smith, A. (1995). La teoria dei sentimenti morali. Milano: Rizzoli

[30] Spencer, H. (1896), The study of sociology. New York: D. Appleton and Company

[31] Weber, M. (1974). The method of the social-historical sciences, Torino: Einaudi

[32] Williamson, O. E. (1985). The economic institutions of capitalism. New York: Free Press 